\title{
WEAR ANALYSIS OF BY PASS VALVES APPLIED ON REGULATED-TWO-STAGES TURBOCHARGER
}

\author{
Paula Nomura Watanabe ${ }^{1}$, Milton Dias Júnior ${ }^{2}$ and Lauro Yutaka Takabatake ${ }^{1}$ \\ ${ }^{1}$ BorgWarner Brasil Ltda, Itatiba, SP, Brazil \\ ${ }^{2}$ Laboratory of structural Dynamics and Machines, Faculty of Mechanical Engineering, \\ UNICAMP, Campinas, SP, Brazil \\ E-mails: pnomura@borgwarner.com, Milton@fem.unicamp.br, \\ ltakabatake@borgwarner.com
}

\begin{abstract}
The new emission legislations, demand, from vehicle manufactures, the development of technologies to improve fuel consumption and pollutants emission. Following this trend, the turbocharging systems innovate together and release new turbocharger architectures in the market. One of them is the regulated-two-stages Turbocharger, which delivers higher efficiency in a broader engine speed range. In this system, there are two turbochargers, the High and Low Pressure stages. The former has a bigger influence on the low engine speeds, and the latter in the higher engine speed. Between both stages there is a ByPass valve that allows the gas flow to reach the Low Pressure stage, when needed.

In this paper, a wear analysis to understand the wear rate between shaft and bushing of the Bypass valve is presented. This study started in two fronts, the first one is on the wear measurements of high mileage components. Using a precise tridimensional equipment, shaft and bushing had their diameters measured along the whole length over 20.000 points. This data was the input to study the wear profile, depth and shape. As well as predict contact area and total wear volume.

The second front is based on measurements of forces and displacements acting on the pair shaft-bushing. These measurements were performed on real vehicle running a representative application where wear was detected. The dynamic interaction between these forces and the shaft and bushing was essential to explain the wear behavior and understand the influence of each force component.
\end{abstract}

All this experimental data was used as input to the wear equation, developed from wear theory and can be used to evaluate impact of new designs.

\section{INTRODUCTION}

This paper proposes a calculation for wear rate based on integer of the pressure acting on the shaft and bushing system, multiplied by a wear coefficient and the contact area between both components. It is based on wear model from (Dickrell \& Sawyer, 2004) [1] that presents the hypothesis of linear wear per shaft rotation cycle, considering complete revolutions, constant contact angle, constant contact pressure and unitary length. Some adaptions were needed, due to the fact that the study case from this paper has an oscillation in 
a small angle, the contact area increases with wear, contact pressure varies with operation condition and length is a dimension that must be taken into consideration.

\section{Typical Turbocharger}

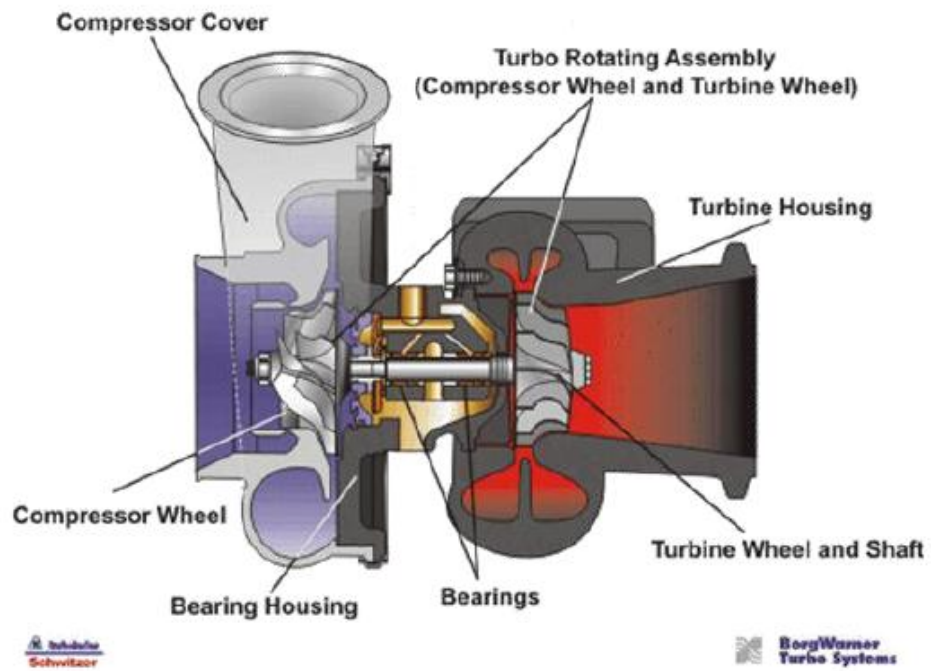

Figure 1The Turbocharger

The Turbocharger from Figure 1 is a mechanic component applied on combustion engines, with the main objectives to increase the output power, reduce engine emissions and decrease fuel consumption. In normal aspirated vehicles, an average of $40 \%$ of total fuel energy is dissipated in the exhaust system. If a turbocharger is applied, part of this energy can be recovered to provide more boost.

The turbine takes advantage of the exhaust energy to spin a shaft, mechanic coupled with a compressor stage. This compressor stage captures the atmosphere air from the air filter and compresses it into the cylinder engine. By pressurizing air into the cylinders, the turbocharger allows the engine to optimize its efficiency, increasing the output power.

Further technologies developed based on this classical concept, have been greatly applied on downsizing engines and on new vehicles. The former targets smaller engines without jeopardizing the power and the latter must accomplish with challenging new emission legislations.

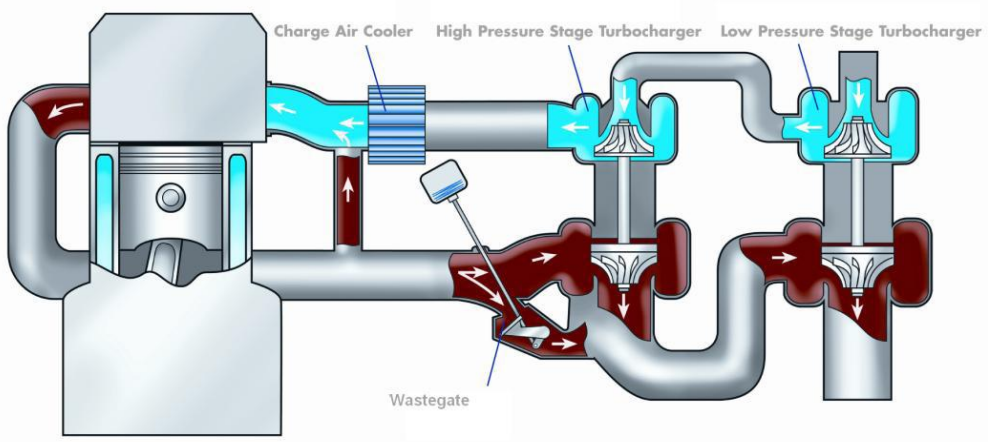

Figure 2 Regulated Two-Stages Turbocharger 
The regulated-two-stages turbocharger consists of two turbochargers in series, a small one called High Pressure stage (HP stage), responsible for the transient response at low engine speeds, and a bigger one called Low Pressure stage (LP stage), that contributes at higher engine speeds. These architectures are most applied in addressing performance targets demanding aggressive boost and/or optimized efficiency in a wide engine speed range.

There are different configurations of R2S systems: series sequential, parallel sequential, including fixed Turbochargers, variable vanes, and different quantities of bypass valves. The most simple represented in the Figure 2 will be described here in order to explain the overall function of the By-Pass valve.

During low engine speeds, the exhaust gas delivered by the engine, flows into the HP turbine, and after that into the LP turbine. Whereas in the compressor side, the air coming from the air filter goes through the first compression stage in the LP, and follows to the HP compressor for the second compression stage.

At higher engine speeds, the system needs to bypass part of the HP turbine flow directly to the LP turbine, and this bypass is done by the ByPass valve showed in the Figure 2 . This valve opens gradually, as the exhaust flow increases, controlling the speed and compensating the energy between both stages.
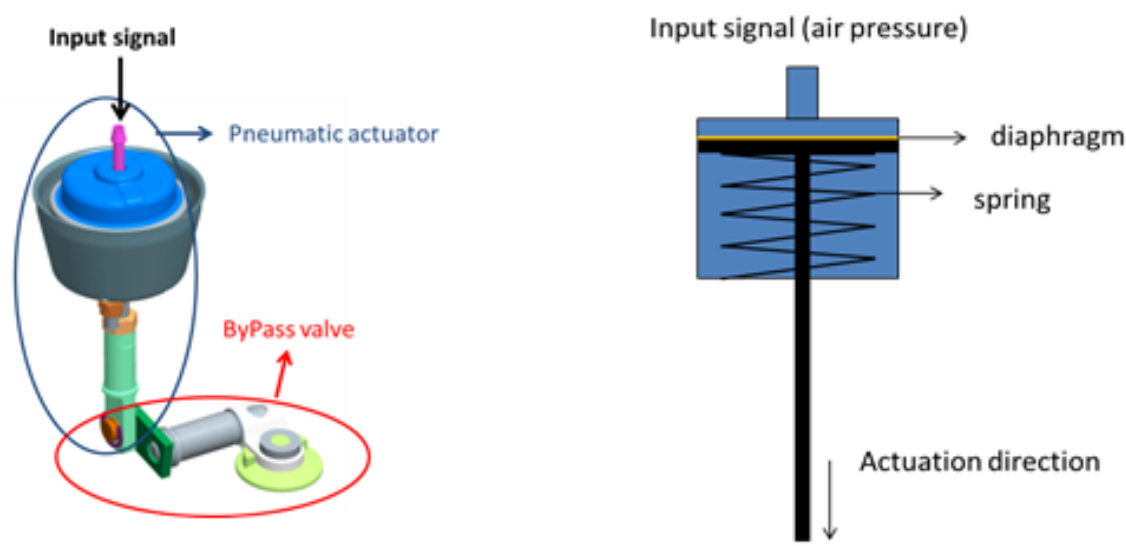

Figure 3a) ByPass valve with actuator b) actuator schematics

The Bypass valve also known as Wastegate valve, has the main function to bypass the exhaust flow from the HP stage to the LP stage, in other turbo architectures, this valve can bypass the exhaust flow from the turbine straight to the exhaust system, therefore it is called Wastegate. This latter function is applied in order to control the maximum turbocharger speed, avoiding over speed failures.

The ByPass valve is actuated by a pneumatic actuator (vacuum or pressurized) or by an electronic actuator. It depends on the precision, packaging and costs required. In this study case, a pneumatic actuator will be addressed. The working concept is very simple: the input signal is pressurized air, which pushes a diaphragm, this diaphragm compresses a spring and pushes a rod, that has an end connected to the Bypass valve assembly (Figure 3). The higher is the input pressure, the higher is the rod displacement, and the higher is the valve plate opening angle.

The input signal is precisely calibrated and controlled by a control valve, which delivers a PWM signal to open or close the Bypass valve. This input signal frequency, added to the overall engine and vehicle vibration, compose the called uncommanded movement. That means all the small movements from the Bypass valve, even when it is fixed in a certain angle or position. In the other hand, commanded movement is the real action of open and 
close the Bypass valve, it is driven by the duty cycle, that means, the real need to release or not the exhaust gas.

The Bypass valve is pressed in the turbine housing as shown in Figure 4. This means that the bushing is static and the shaft oscillates back and forth to open and close the valve plate. The wear between these two components will be studied here in order to deep understand the root cause, critical application condition and possible design solutions.
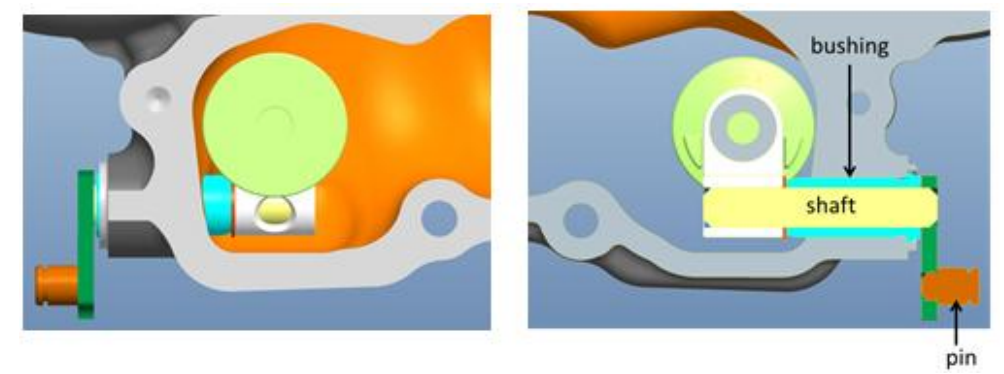

Figure 4 ByPass valve pressed in the Turbine Housing

\section{WEAR THEORY}

(Dickrell \& Sawyer, 2004) [1] used the assumptions of uniform contact pressure and constant applied load to calculate the wear progression in function of cycle or time.

The shaft movement inside the bushing is illustrated in the Figure 5.

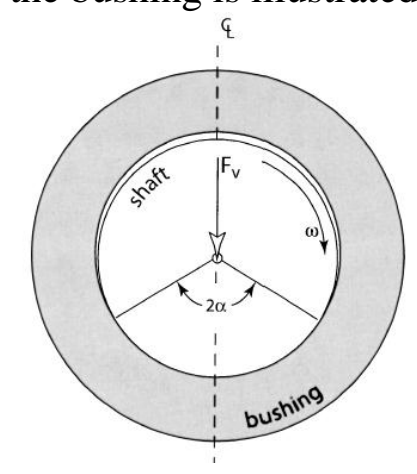

Figure 5 Shaft and Bushing contact

The friction effect in the interface is not considered,

The shaft wear rate can be calculated as the integral of applied load multiplied by the wear rate along the contact length. Assuming the contact angle between the shaft and bushing $2 \alpha$, the initial shaft radius $\mathrm{R}$, and the contact length as uniform and constant, the following formula can be used:

$$
\Delta R_{n}=\int_{0}^{2 \alpha R_{n}} K_{S} P_{n} d s=2 \alpha R_{n} P_{n} K_{S}
$$

$\mathrm{K}_{\mathrm{S}}(\mathrm{mm} 3 /[\mathrm{Nm}])$ is the wear rate of the shaft material and is not a function of cycle number neither time . 


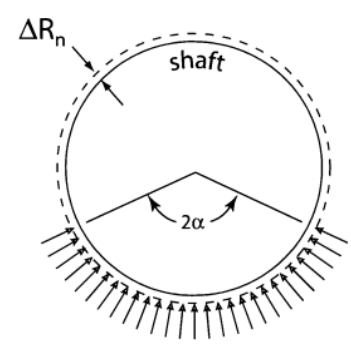

Figure 6 Shaft diameter variation

$F_{R S}\left(F_{\text {act }}, F_{P 3}\right)=$ Resultant Force in the shaft

$\mathrm{hn}=$ bushing recession at cycle $\mathrm{n}$

$\mathrm{hn}=$ change in bushing recession at cycle $\mathrm{n}$

$\mathrm{Kb}=$ wear rate of bushing

$\mathrm{Ks}=$ wear rate of shaft

$\mathrm{n}=$ cycle number

$\operatorname{Pn}\left(F_{\text {act }}, F_{P 3}\right)=$ interface pressure at cycle $\mathrm{n}$

$\mathrm{Rn}=$ shaft radius at cycle $\mathrm{n}$

$\Delta \mathrm{Rn}=$ change in shaft radius at cycle $\mathrm{n}$

$\mathrm{w}=$ depth of contact into the page

$\alpha=$ contact subtend angle

$\omega\left(F_{\text {act }}, F_{P 3}\right)=$ rotational speed

In this study case, the premises used by (Dickrell \& Sawyer, 2004) [1] are not valid. The contact arc is actually a contact area, that varies with wear or cycle. The applied load is distributed in the contact area and is linear along the shaft/bushing length.

Due to the shaft/bushing length additional parameter, the wear rate will be a double integral of the applied force in certain area, multiplied by the length $\mathrm{z}$ and the contact arc, which is radius along the contact angle ${ }^{\propto}$. As written in Equation below

$\Delta R=K_{s} \iint \frac{F(z, t)}{A(l w)} R(l w) d \propto d z$

This equation is equivalent to $\Delta \boldsymbol{R}_{n}=\int_{0}^{2 \alpha R_{n}} \boldsymbol{K}_{s} \boldsymbol{P}_{n} d \boldsymbol{s}=\mathbf{2} \alpha \boldsymbol{R}_{n} \boldsymbol{P}_{n} \boldsymbol{K}_{s}$ from

$$
F\left(z_{t} t\right)
$$

(Dickrell \& Sawyer, 2004) [1], but $P_{n}$ is $\overline{A(l w, t)}$ and $d s$ is $R(l w) d \propto d z$.

The forces acting on the ByPass valve are harmonic, and distributed linearly along shaft/bushing length, therefore it is a function of time and length. Measurements show that contact starts as a contact point, increasing to a contact area, which is a function of wear depth $\mathrm{lw}$ and time. The radius is a function of wear depth.

$$
\begin{aligned}
& \Delta R=K_{s} \frac{R(l w)}{A(l w, t)} \iint F(z, t) d \propto d z \\
& \frac{\Delta R}{\Delta t}=K_{s} \iint \frac{F\left(z_{i} t\right)}{A\left(l w_{t} t\right)} R(l w) d \propto d z
\end{aligned}
$$




$$
\frac{\Delta R}{\Delta t}=K_{s} \frac{R(l w)}{A(l w, t)} \iint F(z, t) d \propto d z
$$

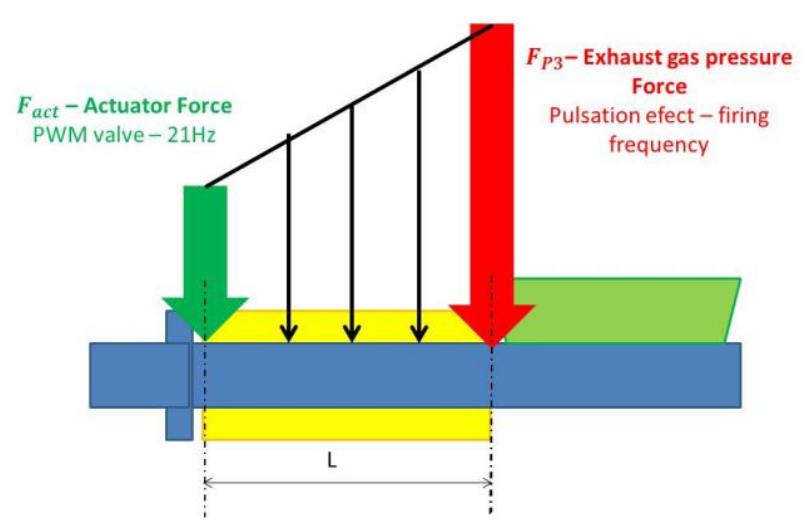

Figure 7 Schematic forces acting on the ByPass valve

The component of the exhaust gas pressure force perpendicular to the shaft will be called as $F_{1}(t)$ here and the actuator force is $F_{2}(t)$. The equation to represent both force along the total length $\mathrm{L}$ is:

$$
F(z, t)=F_{2}(t)+\left(\frac{F_{1}(t)-F_{2}(t)}{L}\right) z
$$

Replacing $F(z, t)$, and applying the contour integral:

$$
\begin{gathered}
\oint P d \alpha+Q d z=\iint \frac{\partial Q}{\partial \alpha}-\frac{\partial P}{\partial z} d z d \alpha \\
\frac{\partial Q}{\partial \alpha}-\frac{\partial P}{\partial z}=F_{2}(t)+\left(\frac{F_{1}(t)-F_{2}(t)}{L}\right) z \\
\frac{\partial P}{\partial z}=0 ; \frac{\partial Q}{\partial \alpha}=F_{2}(t)+\left(\frac{F_{1}(t)-F_{2}(t)}{L}\right) z \\
\oint Q d z=\oint F_{2}(t) z+\left(\frac{F_{1}(t)-F_{2}(t)}{L}\right) \frac{z^{2}}{2} d z \\
\frac{\Delta R}{\Delta t}=K_{s} \frac{R(l w)}{A(l w, t)} \oint F_{2}(t) z+\left(\frac{F_{1}(t)-F_{2}(t)}{L}\right) \frac{z^{2}}{2} d z \\
\frac{\Delta R}{\Delta t}=K_{s} \frac{R(l w)}{A(l w, t)} 2 \int_{0}^{z m(l w)} F_{2}(t) z+\left(\frac{F_{1}(t)-F_{2}(t)}{L}\right) \frac{z^{2}}{2} d z \\
\frac{\Delta R}{\Delta t}=\sum K_{s} \frac{R(l w)}{A(l w, t)}\left[F_{2}(t) z^{2}+2\left(\frac{F_{1}(t)-F_{2}(t)}{L}\right) \frac{z^{3}}{3}\right]_{0}^{z m(l w)}
\end{gathered}
$$

$K_{s}$ - wear coefficient

$F(z, t)$ - Force applied on the shaft and bushing system

$L$ - shaft total length

$l w$ - wear depth 
$A(l w)$ - wear area

$R(l w)$ - shaft or bushing radius

$\propto$ - wear angle

$z$ - wear length

\section{EXPERIMENTAL ANALYSIS}

\subsection{Vehicle and engine measurements}

There were two measurements performed with the same engine type, but in different conditions. The first measurement was done in an engine dynamometer, fitted with a 4 cylinders turbocharged engine and a PWM control valve of $21 \mathrm{~Hz}$. From max engine speed until low idle at an acquisition rate of $100 \mathrm{~Hz}$.

The second measurement was performed on a diesel truck fitted with a 4 cylinders turbocharged engine and a PWM control valve of $150 \mathrm{~Hz}$. The track was a combined cycle of highway, uphill and downhill, very representative of the application cycle. The total track length is $132,6 \mathrm{~km}$ and acquisition rate of $1000 \mathrm{~Hz}$.

\subsubsection{Exhaust pressure measurements}

There was a pressure transducer on the turbine inlet (P3) and another one in the actuator inlet (Pact), as showed in Figure 8.

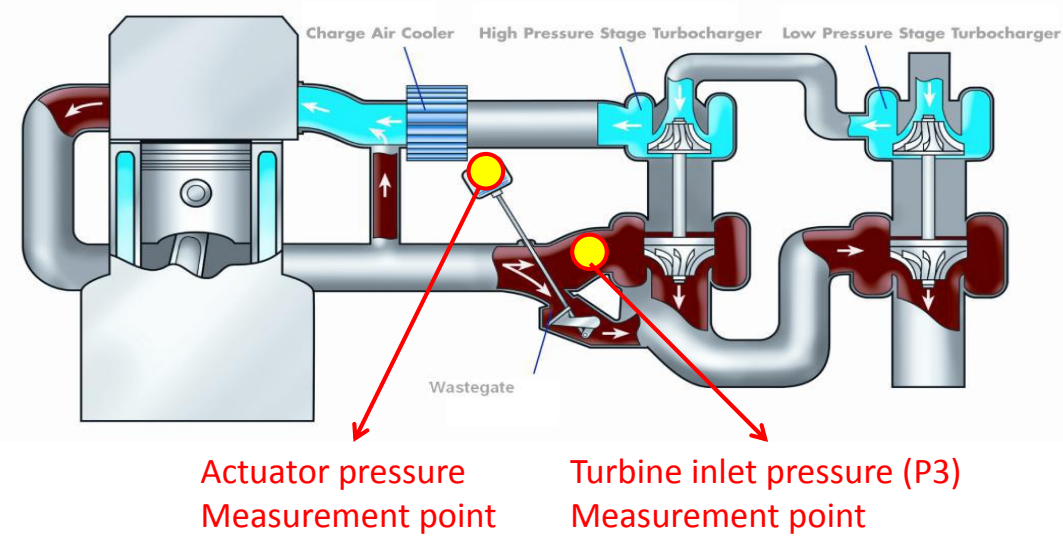

Figure 8 Measurement points in the vehicle

The exhaust gas pressure measured pushes the valve plate to the opening position, and the actuator pressure is the command to close the valve. As demonstrated in the Figure 9 


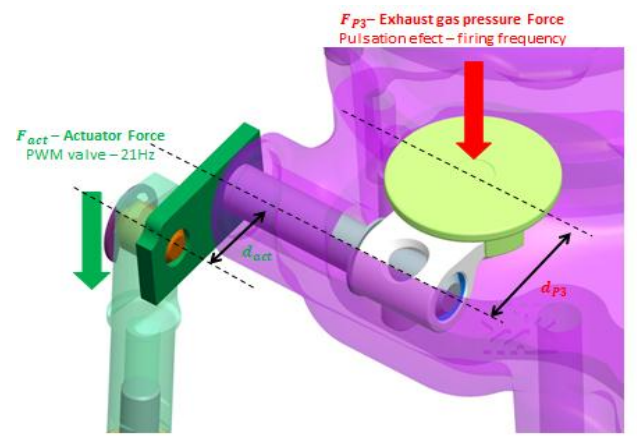

Figure 9 ByPass valve forces

The force coming from the exhaust pressure, is first of all calculated multiplying the valve plate area and the pressure. This force is than decomposed in the perpendicular and parallel direction of the shaft and bushing for every different angular position. This is simple once all design parameters of the complete valve are known.

$F_{P 3}=P_{3} \times A_{\text {valve plate }}$

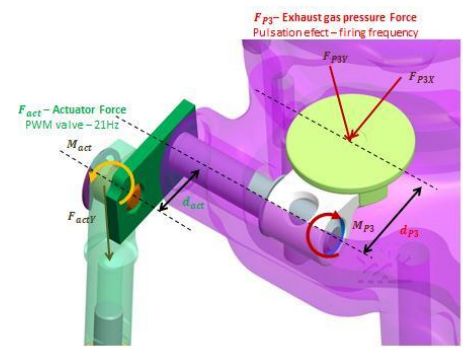

Figure 10 Forces decomposition
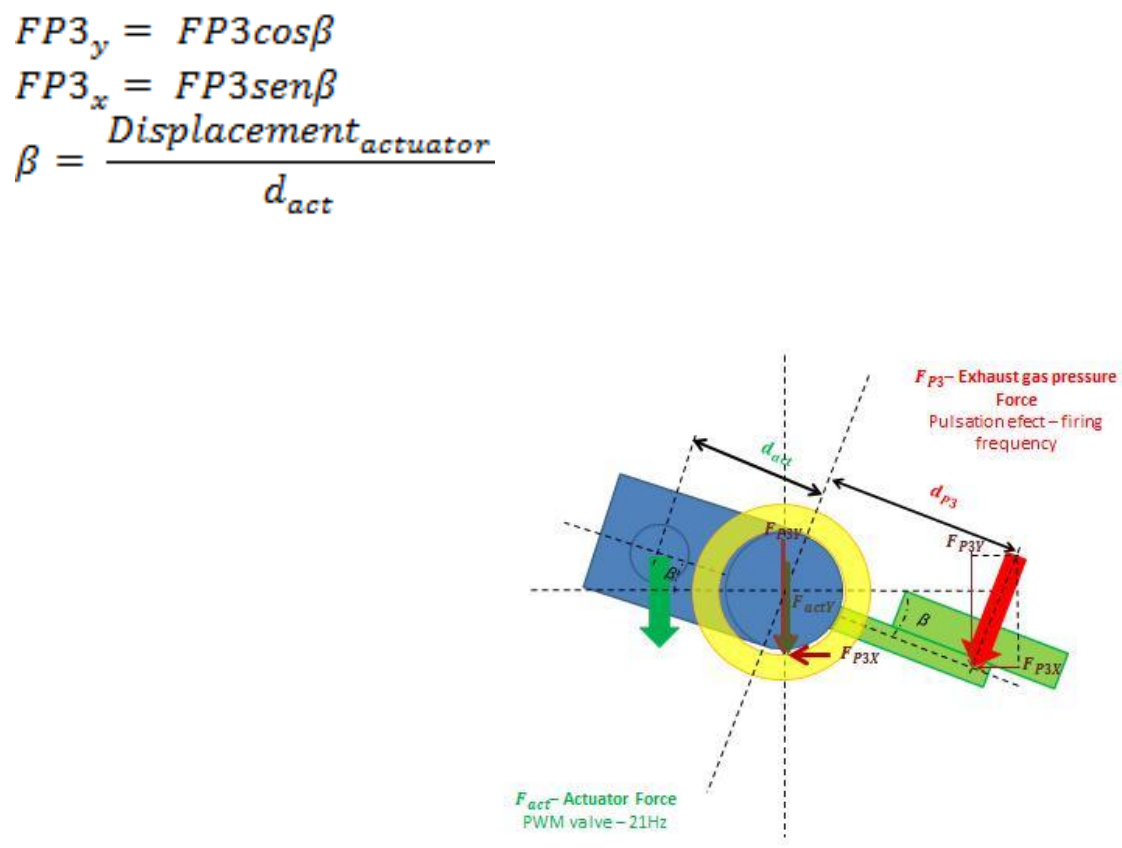

Figure 11 - Schematic Forces componentes 


\subsubsection{Actuator pressure measurements}

The actuator force does not need to be decomposed since the connection between the actuator rod and the valve is not fixed. So the actuator force is always applied perpendicular to the shaft. It is calculated multiplying the actuator inlet pressure measured by the diaphragm area and subtracting the spring force that works in the opposite direction.

$$
F_{\text {act }}=P_{\text {act }} \times A_{\text {diaphragm }}-F_{\text {spring }}
$$

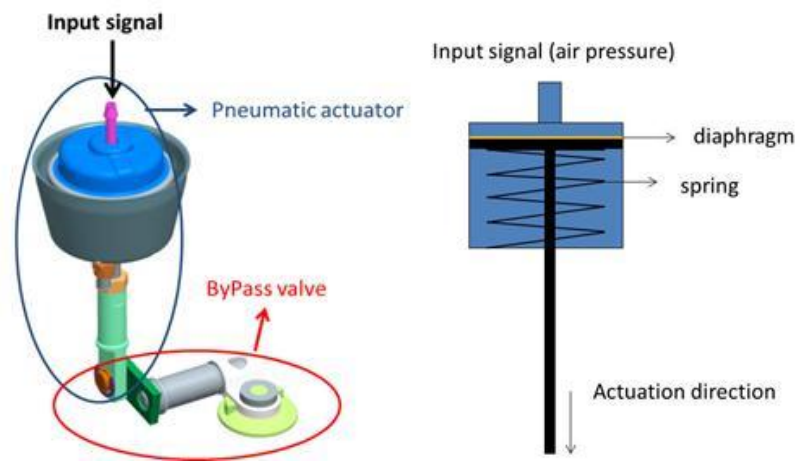

Figure 12 - a) Actuator and ByPass valve connected b) schematic actuator components

The $\mathrm{x}$ component of the exhaust force has a small influence in the wear when comparing to the y component due to the small opening angle verified in the measurements.

\subsubsection{Actuator displacement measurements}

The difference between the exhaust gas pressure and the actuator force generates an angular displacement in the valve plate position in direction of opening or closing it. This angular displacement could not be measured, but the linear displacement of the actuator rod was measured.

Analyzing the data from engine dyno, with the $21 \mathrm{~Hz}$ PWM control valve, it was possible to observe that the actuator displacement measurements have a great concentration of micro movements lower than $0.1 \mathrm{~mm}$, as seen in Figure 13.

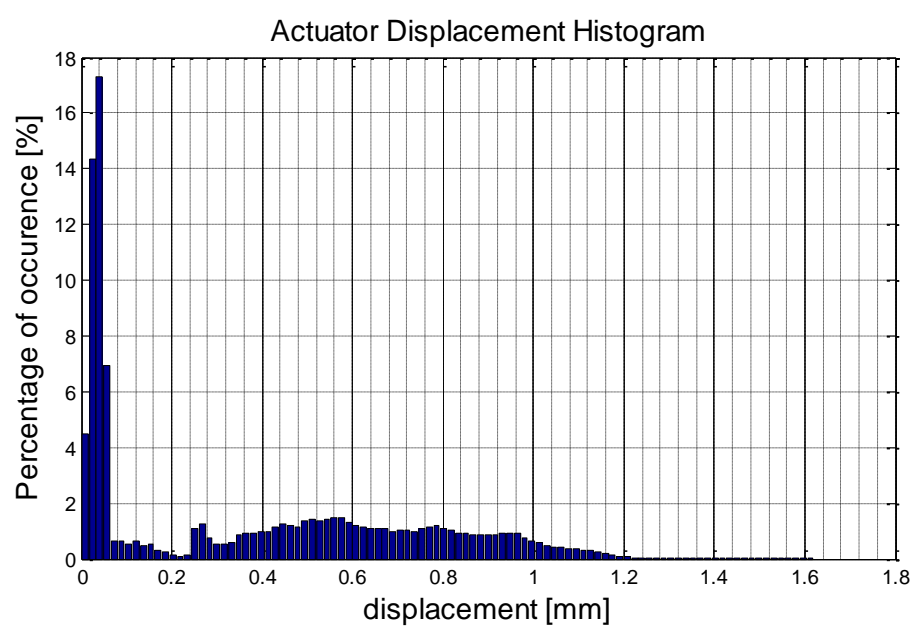

Figure 13- 21Hz PWM control valve - actuator displacement 
The $21 \mathrm{~Hz}$ frequency is highlighted in the actuator displacement waterfall graphic. This frequency matches with the PWM valve operating frequency

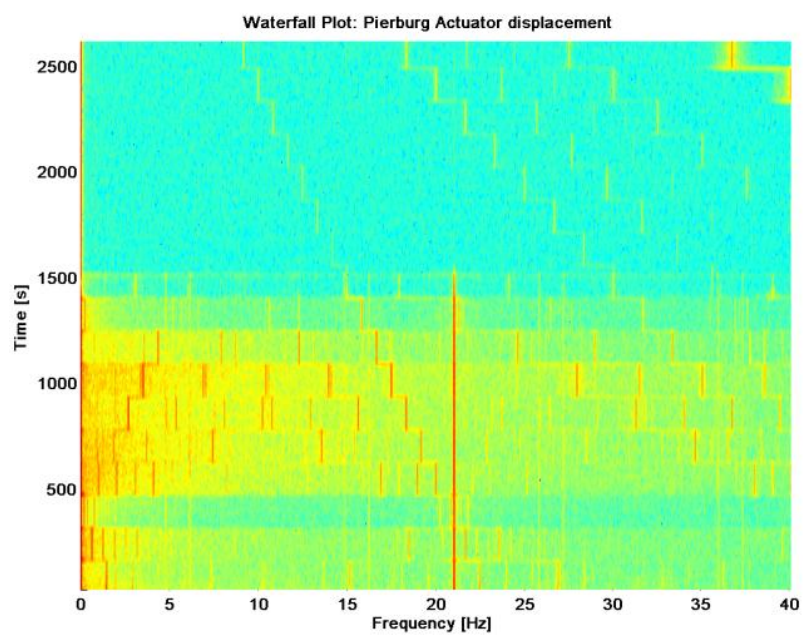

Figure 14- 21Hz PWM Actualtor Displacement Waterfall

Analyzing the data from vehicle, with $150 \mathrm{~Hz}$ PWM control valve, it was possible to observe that the actuator displacement measurements still present a great concentration of micro movements lower than $0.1 \mathrm{~mm}$, as seen in Figure 15.

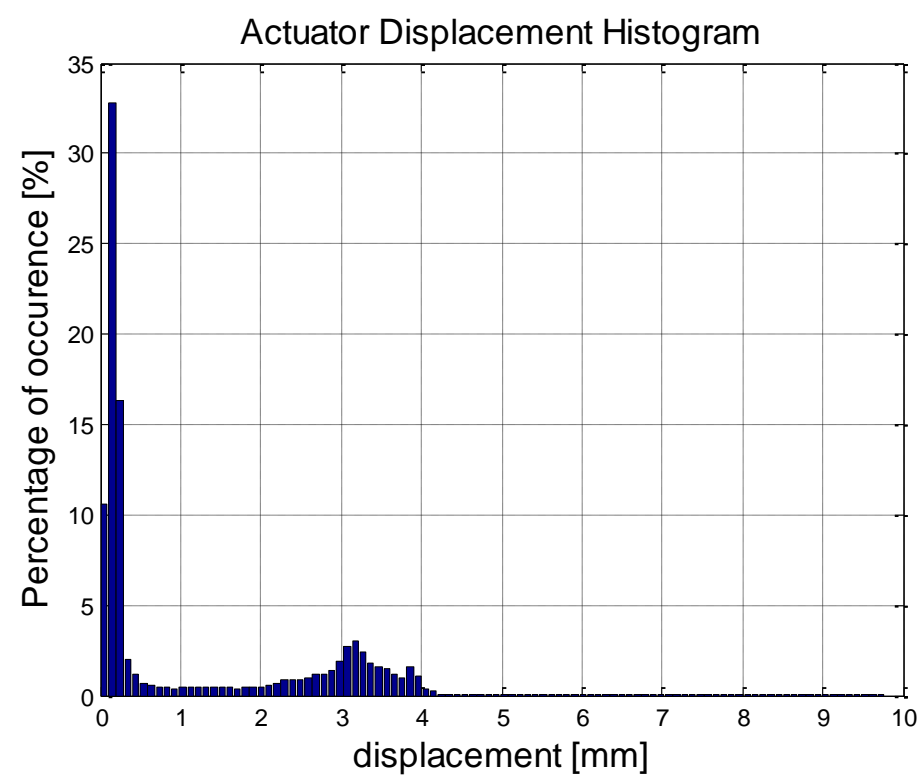

Figure 15 150Hz PWM control valve - actuator displacement

But the critical frequency of $21 \mathrm{~Hz}$ is no longer highlighted in the actuator displacement waterfall graphic. Neither the $150 \mathrm{~Hz}$ frequency is presented as showed in Figure 16 


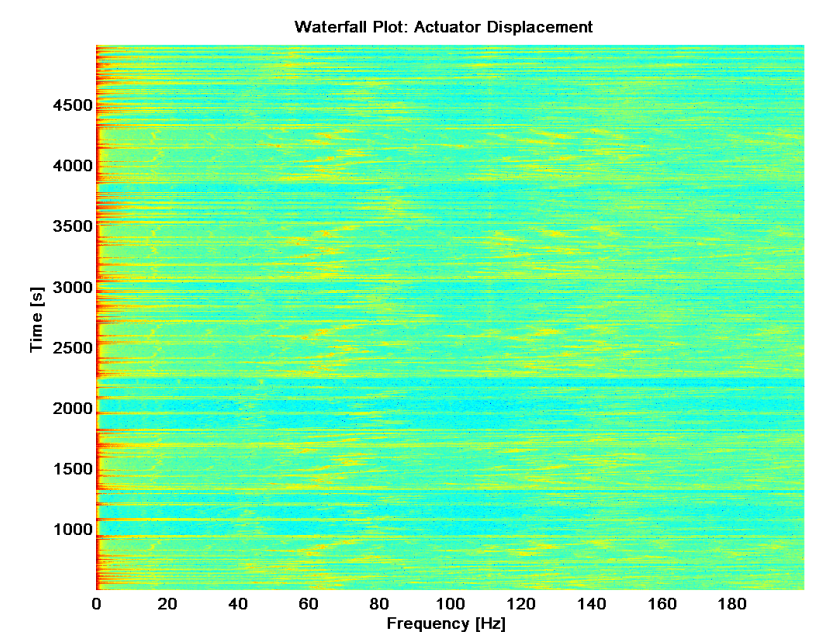

Figure $16150 \mathrm{~Hz}$ PWM control valve - actuator displacement

The order map showed in Figure 17 presents a critical order, which is the engine second order.

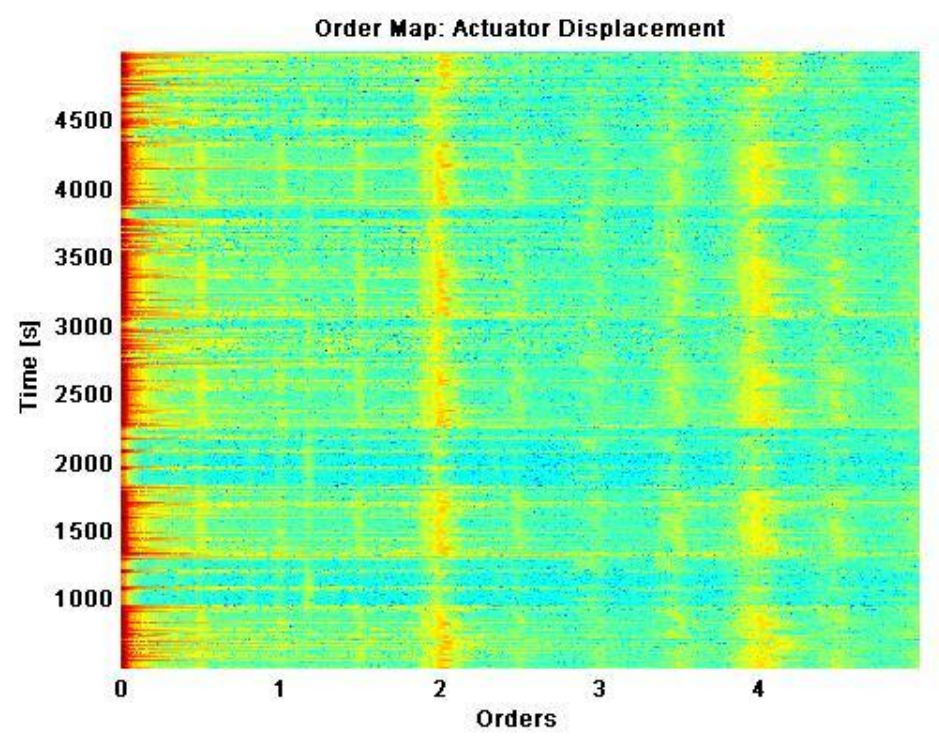

Figure 17150 Hz PWM control valve - actuator displacement- Order map

\subsection{Wear measurements}

In order to measure the By-pass valve, the shaft is cut from the lever arm to draw it from the Turbine Housing, carefully cleaned up, and fixed in a device to keep the shaft parallel to the $\mathrm{z}$ axis from the tridimensional measurement machine as Figure 18. Beginning from the edge close to the valve plate, the machine starts reading the $\mathrm{x}$ and $\mathrm{y}$ position of each point in the perimeter of the shaft, in the whole $360^{\circ}$, keeping the same $\mathrm{z}$ position. After the complete ring is measured, the machine displaces $1 \mathrm{~mm}$ in the $\mathrm{z}$ direction towards the cut end and measures the following ring. 


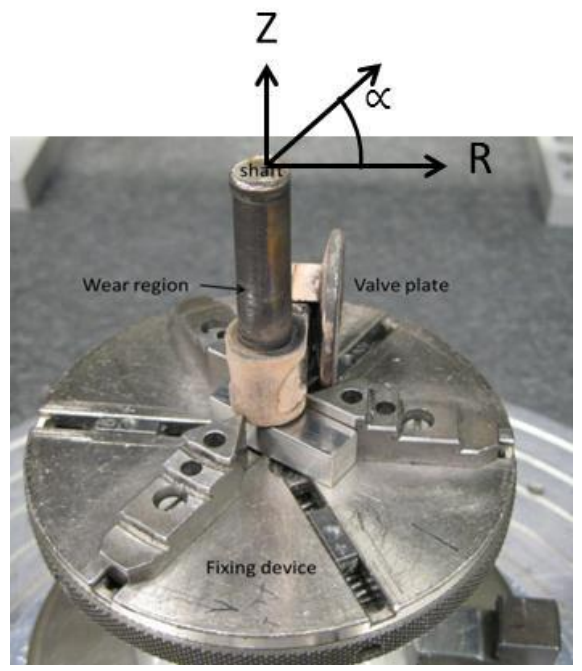

Figure 18 Fixing device for wear measurement

The complete data is collected, processed and transformed into cylindrical coordinates to plot the graphic from Figure 19. An interpolation of the points measured was necessary to guarantee that the whole cylinder surface can be plotted. The colors mean the depth of the wear. The hotter is the color, the deeper is the wear in that region (the smaller is the diameter). It is possible to detect that the initial contact area is a point, and not a line as general cylindrical contact theory. This is due to the fact that the forces in both ends of the shaft are not equalized, leading to a slight tilt.

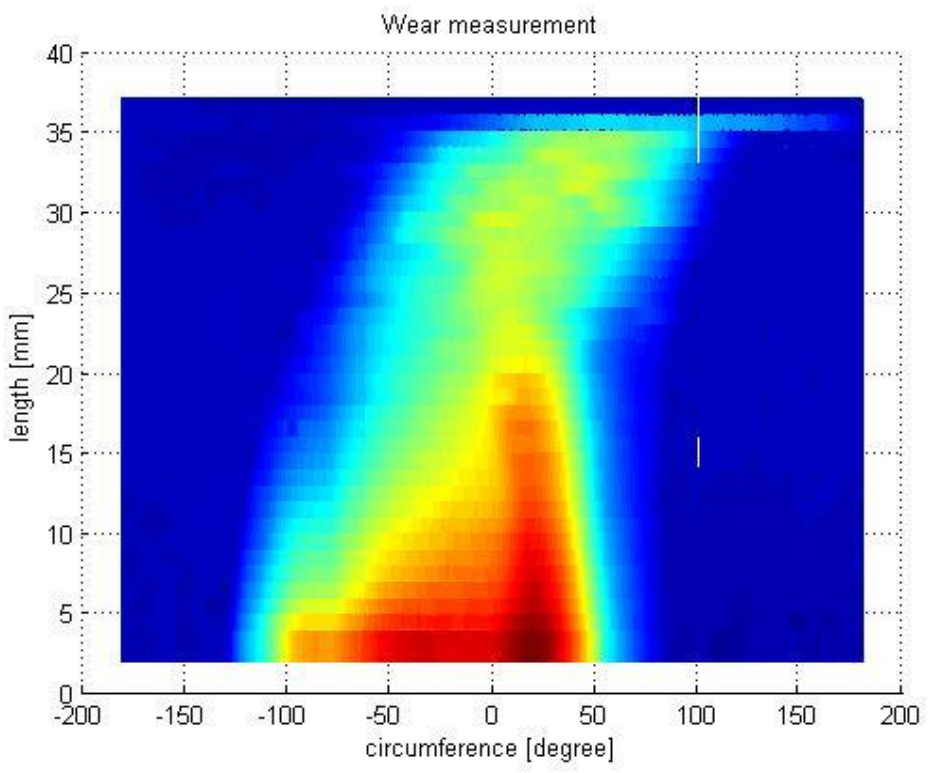

Figure 19 - Shaft wear measurement from a 4 cyl truck (T4.2)

The very deepest point in the worn region can be considered as the first contact point, and the progression of this contact area is modeled in order to give a contact area in function of wear depth. 


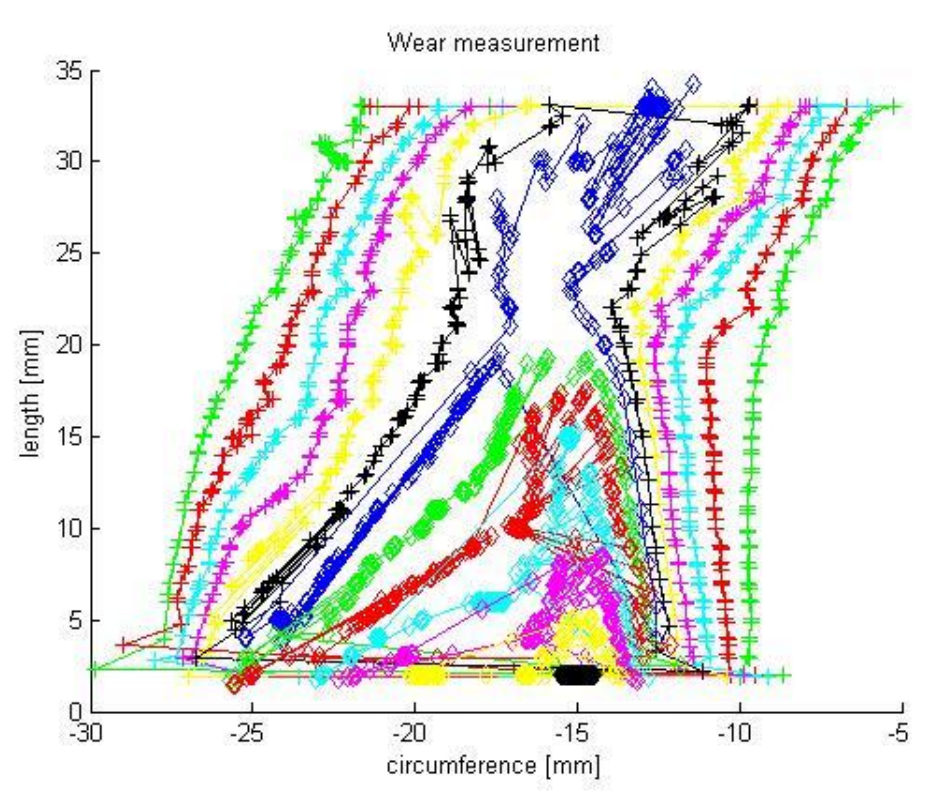

Figure 20 Shaft Wear area bounded for each wear depth T4.1

Second step was to draw the contour line of each wear depth, bounding its contact area (Figure 20). After that, it was possible to calculate the contact area of every wear depth, the length and width of the wear area for each wear depth and the cumulative volume. All this information is needed to input in the wear formula mentioned before.

\subsection{Wear rate calculation based on measurements}

The development of (Dickrell \& Sawyer, 2004) [1] theory was applied using the measured pressures in the vehicle and the wear parameters calculated from durability measurements. Unfortunately the pressure acquisition was only performed in one vehicle type (truck 4 cylinders). In order to have all the inputs to the formula, it is necessary to have, not only the measured and calculated forces, but also the measured wear parameters on the shaft and bushing, as radius, area, depth and length.

As the coefficient wear (Ks) is unknown, the wear rate calculation will be in function of this value, so:

$$
\frac{\Delta R}{\Delta t} \times \frac{1}{K_{s}}=\sum \frac{R(l w)}{A(l w i t)}\left[F_{2}(t) z m(l w)^{2}+2\left(\frac{F_{1}(t)-F_{2}(t)}{L}\right) \frac{z m(l w)^{3}}{3}\right]
$$

For comparison purposes, the wear rate was calculated varying two design parameters, longer bushing length and bigger bushing internal diameter. The wear rate progression can be seen in Figure 21. 


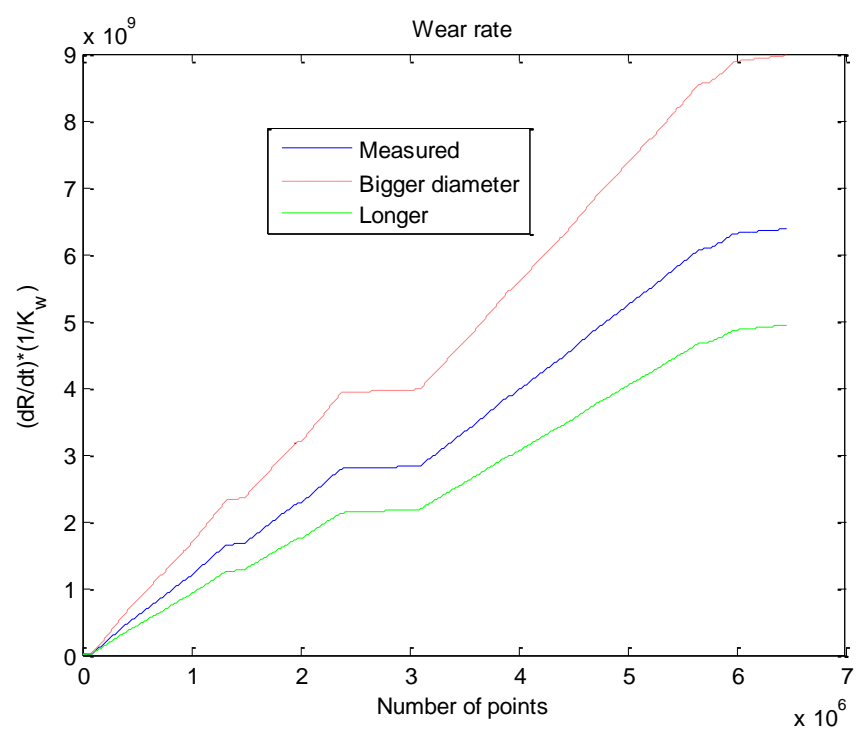

Figure 21 - Wear rate comparison - Different bushing design parameters

It is possible to state that the longer bushing provides a decreased wear rate in comparison to the actual design. And on the other hand, a bigger diameter would decrease bushing lifetime. As shown in Figure 22, for a 50\% longer bushing, there is an average of $30 \%$ wear rate improvement. And for a $50 \%$ diameter increase, there is about $29 \%$ lifetime decrease.

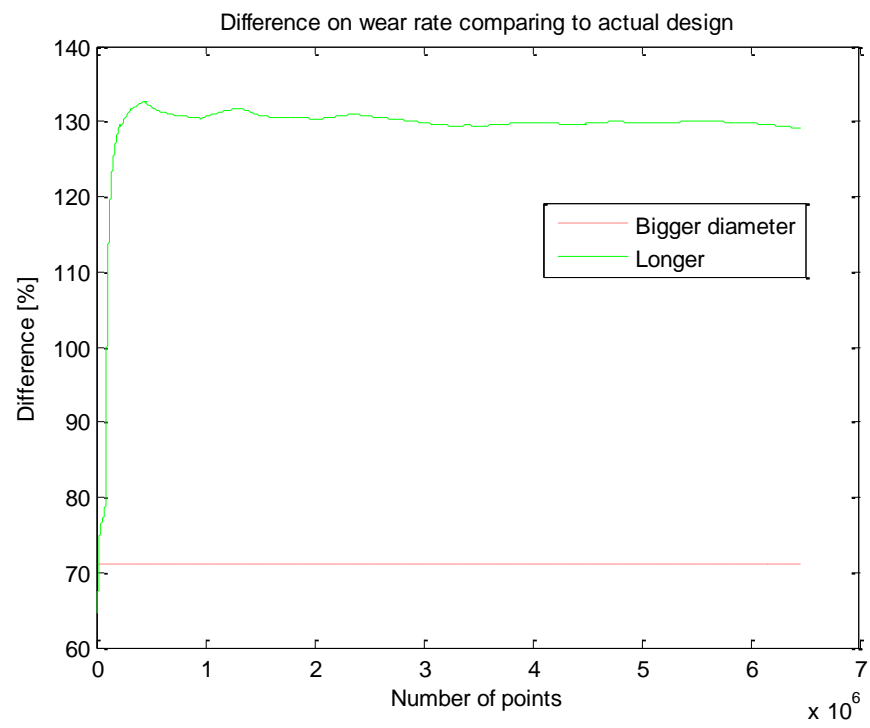

Figure 22 - Bushing - \% comparison to different design parameters

The same calculation was performed using the shaft wear data. It is clear that the bushing wear rate was much higher than the shaft wear rate. In comparison to other design parameters for the shaft, result trend was similar, but quantitatively there was a considerable difference. 


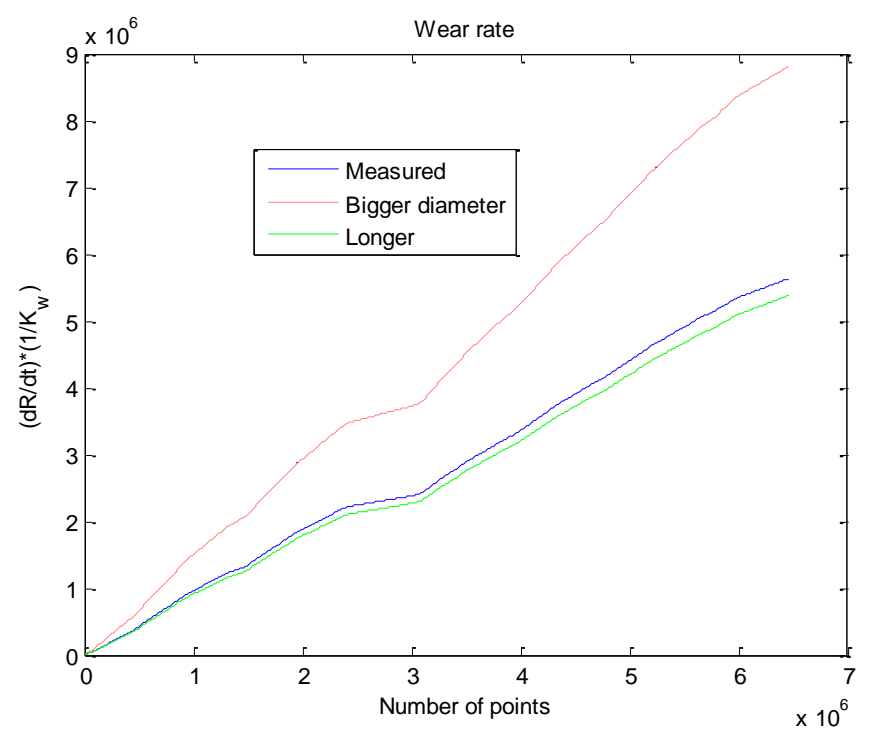

Figure 23 - Wear rate comparison - Different shaft design parameters

The improvement expected by longer bushing is not that significant, only 5\% for a 50\% length increase. And a 50\% bigger diameter brought a $36 \%$ lifetime reduction.

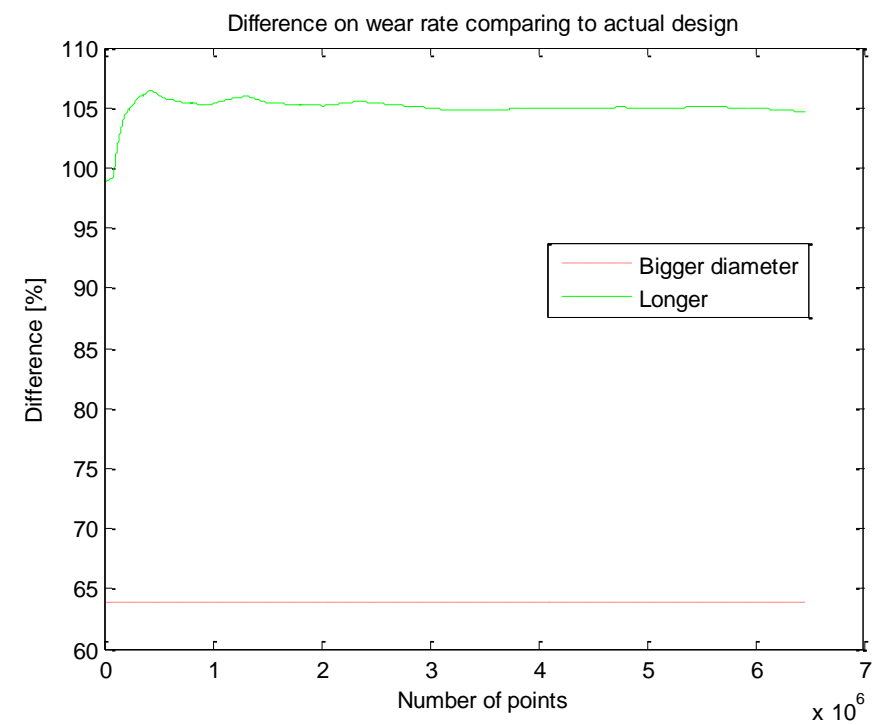

Figure 24 - Shaft - \% comparison to different design parameters

\section{CONCLUSION}

Image processing of wear data was important to extract wear parameters that were missing in the wear calculation. The micro movements from $21 \mathrm{~Hz}$ control valve may influence on wear, but further durability results with $150 \mathrm{~Hz}$ control valve must be analyzed to confirm statistically this result. There is still a vibration coming from the engine second order influencing on the high concentration of micro movements. Wear rate calculation can be used for comparison purposes. Increasing shaft-bushing length can improve lifetime. 


\section{REFERENCES}

[1] Dickrell, D. J., \& Sawyer, W. G. (2004). Evolution of Wear in a Two-Dimensional Bushing. Tribology Transactions, 47(2), 257-262. doi:10.1080/05698190490439175

[2] Ahmadi, N., Keer, L., \& Mura, T. (1983). Non-Hertzian contact stress analysis for an elastic half space - normal and sliding contact. International Journal of Solids and Structures. Retrieved from http://www.sciencedirect.com/science/article/pii/002076838390032X

[3] Aleksandrov, V. M., Bronovets, M. a., \& Soldatenkov, I. a. (2008). Mathematical modeling of wear of journal bearings in outer space. Journal of Friction and Wear, 29(3), 182-187. doi:10.3103/S1068366608030057

[4] Ciavarella, M., \& Decuzzi, P. (2000). The state of stress induced by the plane frictionless cylindrical contact I. the case of elastic similarity. International Journal of Solids and Structures, 38, 4507-4523.

[5] Ciavarella, M., \& Decuzzi, P. (2001). The state of stress induced by the plane frictionless cylindrical contact II.pdf. International Journal of Solids and Structures, 38, 4525-4533.

[6] Dine, S., Cromer, R., \& Calabrese S. J. (1996). Redesigning IVIechanical Systems for Low Wear Using System Dynamics Modeling W^, 118(April), 0-7.

[7] Drozdov, Y. N. (1976). Development of a Method for the calculation of the life of a dry frictional contacts under extreme operating conditions. Wear, 38, 217-223.

[8] Johnson, K. L. (1987). contact mechanics. New York: Cambridge University Press.

[9] Kunert, K. von. (1961). Spannungsverteilung im Halbraum bei elliptischer Flächenpressungsverteilung über einer rechteckigen Druckfläche. Forschung, (1). doi:DK $539.319: 539.383: 531.252 .001 .5$

[10] Mosleh, M., Saka, N., \& Suh, N. P. (2002). A mechanism of high friction in dry sliding bearings, 252, 1-8.

[11] Nayak, L., \& Johnson, K. L. (1979). Pressure between elastic bodies having a slender area of contact and arbitrary profiles. International Journal of Mechanical Sciences, 21(4), 237-247. doi:10.1016/0020-7403(79)90067-5

[12] Wen, J., \& Khonsari, M. M. (2009). Thermomechanical Coupling in Oscillatory Systems With Application to Journal Bearing Seizure. Journal of Tribology, 131(2), 021601. doi:10.1115/1.3071976

[13] Williams, J. A. (1999). Wear modelling: analytical, computational and mapping : a continuum mechanics approach, 1-17. 